Research Article

\title{
Study on Dynamic Evolution of Roof Crack and Support Timing of Secondary Tunneling for Large Section Open-Off Cut in Deep Mines
}

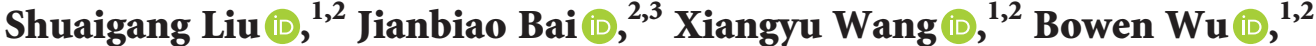 \\ Guanghui Wang $\mathbb{1})^{1,2}$ Yanhui Li $\left.\mathbb{1}\right)^{1,2}$ and Jun $\mathrm{Xu}^{4}$ \\ ${ }^{1}$ School of Mines, China University of Mining and Technology, Xuzhou 221116, China \\ ${ }^{2}$ State Key Laboratory of Coal Resources and Safe Mining, China University of Mining and Technology, Xuzhou 221116, China \\ ${ }^{3}$ College of Mining Engineering and Geology, Xinjiang Institute of Engineering, Urumqi 830023, China \\ ${ }^{4}$ School of Science, Yangzhou Polytechnic Institute, Yangzhou 225127, China
}

Correspondence should be addressed to Jianbiao Bai; baijianbiao@cumt.edu.cn

Received 18 March 2021; Revised 29 March 2021; Accepted 5 April 2021; Published 21 April 2021

Academic Editor: Zhijie Zhu

Copyright $\odot 2021$ Shuaigang Liu et al. This is an open access article distributed under the Creative Commons Attribution License, which permits unrestricted use, distribution, and reproduction in any medium, provided the original work is properly cited.

\begin{abstract}
The stability of large section open-off cut in deep mines (LODM) is the key factor affecting the normal equipment installation and safe mining in fully mechanized top-coal caving face. The mechanical model shows that the deflection of the roof of the LODM is proportional to the cubic of span. In this paper, UDEC Trigon model is established, and the parameters of different coal measures strata are modified in detail. The evolution law, failure mode, and damage degree of roof cracks in secondary tunneling are studied, and the roof support effect is analyzed. The numerical simulation results show that the process of roof crack evolution after the primary excavation section and the second excavation section can be divided into three stages according to microseismic activities, and the reasonable supporting time can control the propagation of roof microcracks and reduce the development height of macrocracks. The rock bridge existing in the roof rock stratum after the combined support of long and short anchor cables can effectively limit the formation of macrocracks and their interaction; especially the key support in the interface area can reduce the development height of roof cracks in secondary tunneling and weaken the damage degree of roof rock stratum in the LODM. The field test shows that the moved volume of rib-to-rib and roof-to-floor of the LODM is stable at about $350 \mathrm{~mm}$ and $550 \mathrm{~mm}$, respectively. The numerical simulation in this paper is helpful to understand the failure mode of roof in LODM with large mining height and provides a method for the design of its control technologies.
\end{abstract}

\section{Introduction}

Open-off cut is the place for equipment installation and mining initiation in coal mining face. With the gradual improvement of mechanization degree in fully mechanized top-coal caving face, the width of open-off cut in fully mechanized top-coal caving face also gradually increases. At the same time, in recent years, with the depletion of shallow coal resources, many mines have begun to move to the deep part [1-5]. Compared with the open-off cut under conventional conditions, the LODM has the characteristics of high in situ stresses, high ground temperatures, high permeability, large span, absciss layer, and easily separated and fell roof and low coal seam strength $[6,7]$. There are many factors that affect the stability of the LODM, including section shape, geological conditions, ground stress, tunneling mode, supporting time, and supporting strength [8]. The service time of open-off cut is from the beginning of tunneling to the start of mining when the equipment is successfully installed and debugged in working face. Different from the shafts, main roadways, headgates, and tailgates, the service time of open-off cut is generally short and only a few months. If we pay attention to the support strength and density in order to control the deformation of 
surrounding rock in the LODM, it will lead to excessive support, which will not only increase the cost, but also lead to serious consequences such as difficulty in preliminary roof caving and in roof management of working face for fully mechanized top-coal caving face. If the support strength and density are reduced in consideration of its short service time, it will lead to insufficient support, which will not only easily lead to roof falling accidents and threaten workers' life safety, but will also lead to serious deformation and damage of surrounding rock, thus making the equipment unable to be installed. And it is necessary to repair the roof or floor again; if not, it will affect the safety and efficient production of the mine [9-12].

A lot of research has been done on the failure mode and control technology of roof in the LODM. Yin [13] analyzes the mechanical structure of roof in large section roadway and derives differential equations based on elastic foundation beams to obtain the variation law of bending moment and roof subsidence with roof span. The structural characteristics of roof support by anchor truss and load distribution characteristics of anchor truss structure are studied, and the BP neural network active support design system for thick coal seam roadway of large section is developed to determine the key support parameters of large section roadway. Zhang et al. [14] obtained through physical similarity simulation that the roof of large section open-off cut with large mining height is easy to fall and the corner is easy to be damaged, and the roof sinks obviously after the openoff cut is expanded. According to the failure characteristics of the open-off cut, the treatment measures such as improving the stress state of the corner, supporting the roof in time, and reducing span support are put forward. He et al. [15] establish Hooke-Kelvin concatemer model of surrounding rock according to the failure characteristics of surrounding rock in large section open-off cut with large mining height, analyzes the key influencing factors of anchor cable tension, and reveals the interaction mechanism between roof pressure arch and anchor cable in open-off cut. Compared with the difference of action mechanism between single anchor cable and truss anchor cable, the control technology of truss surrounding rock with composite anchor cable is put forward, which achieved good results. Xie et al. [16] established FLAC ${ }^{3 D}$ numerical calculation model, analyzed the distribution characteristics of effective stress field of the roof of the LODM, constructed the load-bearing structure of anchored rock beam, obtained the analytical expression of maximum shear stress under compound influence function, and defined the cooperative control principle of the roof of the LODM as well as load-bearing structure of anchored rock beams of two sides of roadway. Peng et al. [17] put forward a support method combining double-layer I-bar closed support with grouting for large section roadway under the condition of high stress broken surrounding rock, and the field monitoring deformation is less than $25 \mathrm{~mm}$. Zhang et al. [18] simulated the failure mechanism of a large section roadway with a depth of $1 \mathrm{~km}$. The results show that the soft rock property and high original rock stress are the main factors leading to the instability of the deep roof and put forward the joint control technologies such as long anchor rod and anchor cable, ring support, and grouting.

Many studies have discussed the influence of support schemes on roof failure control, but the continuum model usually underestimates the effectiveness of support units, because the continuum method can not simulate the inhibition of roof crack opening and sliding [19-25]. Using discontinuous or discrete elements to understand the failure mechanism of roof in the LODM and the interaction of support units is of great significance to guide the roadway support strategy [26]. Bai et al. [27] used UDEC Voronoi method to study the progressive failure process of roadway roof of large section, and the results showed that shear cracks dominated the roadway roof, and they put forward reasonable control technology. Gao et al. [28] used UDEC Trigon model to simulate the shear failure process of the roof in large section and successfully captured the shear failure of roof characterized by crack initiation and propagation. The results showed that the shear failure of roadway roof started at the corner of roadway, then gradually spread to the depth of roof, and finally formed a large-scale roof failure. Moreover, it simulated the role of anchor rod support in limiting the shear failure of roadway roof. Anchor rod support limited the expansion of roof rock, reduced the failure of rock bridge, and ensured the rock strength, thereby significantly reducing the subsidence of the roof of the large section roadway. Zhang et al. [29] analyzed the roof failure characteristics of large section roadway by using UDEC polygon method and put forward a support scheme involving key area reinforcement and high-strength anchor rod, and the deformation of large section roadway was controlled within $550 \mathrm{~mm}$. Yin et al. [30] established a numerical simulation model of surrounding rock of large section roadway by using $3 \mathrm{DEC}$. The results show that obvious cracks will occur at both ends of the roof under the action of shear stress. With the upward propagation of cracks at the roof absciss layer and the extension of transverse cracks, the cracks above the large section roof run through a dangerous crack zone. On this basis, an optimized support scheme is given.

Although there are some understandings on the failure mechanism of roof in the LODM, it is relatively rare to study the failure process and control of roof by discrete element method [31-33]. The method of secondary tunneling is adopted in the LODM. The primary excavation section is affected by the secondary excavation section, and the start, slip and expansion of roof strata cracks are serious. How to control the roof in the interface area of the two excavations, the timing of reinforcement and support, and the support strength are the core points of the LODM. In this paper, discrete element model is used to study the failure process of roof in the LODM, to determine the reasonable support timing of two excavation sections, and to systematically study the laws of crack propagation, failure mode, and damage degree of roof in the LODM. On this basis, the control effects of three support schemes on roof in open-off cut are put forward. Finally, the support timing and key control points of the LODM are put forward, the control technical parameters of open-off cut in 5202 working face of 
Xin'an coal mine are determined, and the effect of supporting is monitored and evaluated on site. The research provides reference and referential significance for open-off cut stability research and supporting design under similar engineering geological conditions.

\section{Case Study}

2.1. Geological and Mining Conditions. Xin'an coal mine is located in Pingliang City, Gansu Province, China, as shown in Figure 1(d). The mine adopts longwall mining method to exploit $5 \#$ coal, the mining height is $10 \mathrm{~m}$, and the average buried depth of coal seam is about $800 \mathrm{~mm}$. In this paper, the LODM is located in 5202 working face of Xin'an coal mine. The panel of 5202 working face includes three longwall working faces, namely, 5202, 5204, and 5206 working faces. The 5202 working face is the first mining working face in the panel, with an advancing length of about $1500 \mathrm{~m}$ and a width of about $200 \mathrm{~m}$, as shown in Figure 1(c). The width and the height of open-off cut of the 5202 working face are, respectively, $7800 \mathrm{~mm}$ and $3200 \mathrm{~mm}$, as shown in Figures 1(a) and 1(b). The roof consists of fine sandstone and sandy mudstone, while the floor consists of sandy mudstone and fine sandstone. The rock stratum histogram is shown in Figure 2.

\subsection{Mechanical Model of Roof Deformation in the LODM and} Selection of Tunneling Mode. With one-time tunneling mode, the load of the roof bearing the overlying rock gradually increases and the subsidence of the roof also increases. According to the simply supported beam model of material mechanics, the calculation model of the subsidence of the roof in large section open-off cut is established, as shown in Figure 3, and the deflections of the left and right hinge supports in the model are set to zero.

According to the bending moment equation of beam, the value of the following items can be known:

$$
M(x)=\frac{1}{2} q l x-\frac{1}{2} q x^{2},
$$

where $M$ is the bending moment of the beam, $q$ is the load of overlying rock, and $l$ is the span of the beam.

The differential equation of deflection curve of straight beam with uniform cross section is as follows:

$$
E I \omega^{\prime \prime}=-M(x),
$$

where $\omega^{\prime \prime}$ is the deflection of the beam, $E$ is elastic modulus of roof, and $I$ is moment of inertia of roof beam.

Then the approximate differential equation of the deflection curve of roof beam:

$$
\omega=\frac{1}{24} q x\left(l^{3}-2 l x^{2}+x^{3}\right) .
$$

In the middle of the roof beam span $x=l / 2$, and the deflection of the roof beam is the largest, namely:

$$
\omega_{\max }=\frac{5 q l^{4}}{384 E I} \text {. }
$$

When the height $H$ of the roof beam is constant, its moment of inertia is proportional to its $\operatorname{span} l$, and then:

$$
I=\frac{H^{3}}{12} l .
$$

Substitute equation (5) into equation (4) to get

$$
\omega_{\max }=\frac{5 q l^{3}}{32 E H^{3}} .
$$

It can be seen from Formula (6) that the maximum deflection of the roof of large section open-off cut is proportional to the cubic of span $l$. Therefore, a reasonable supporting method must be chosen for the roof and the support should be in time. The way of tunneling in two times is adopted, that is, to excavate an appropriate section through the open-off cut once. After releasing some energy and reasonably supporting the primary excavated section, then excavate to the designed section size. The primary excavated section and its reasonable support can reduce the span and avoid the roof deformation and crack expansion of the LODM from transferring to the deep.

\section{Numerical Simulations of Roof Failure Process of the LODM}

\subsection{Model Setup}

3.1.1. UDEC Trigon Method. In the trigon method, rock mass is expressed as a combination of triangular blocks bonded by internal contact to simulate brittle materials $[28,34]$. It is assumed that each triangular block is an elastic material and is divided into triangular finite difference domains, which cannot fail. Damage caused by shear stress or tensile stress can only occur along the contact surface, which depends on the strength of the contact surface (see in Figure 4).

In the direction of vertical contact, the stress-displacement relationship is assumed to be linear and controlled by stiffness $k_{n}[35]$ :

$$
\Delta \sigma_{n}=-k_{n} \Delta u_{n}
$$

where $\Delta \sigma_{n}$ is the effective normal stress increment and $\Delta u_{n}$ is normal displacement increment. There is a limiting tensile strength, $\tau_{s}^{\max }$, for the contact. If the tensile strength is exceeded, then $\Delta \sigma_{n}=0$.

In the shear direction, the response is governed by a constant shear stiffness. The shear stress, $\tau_{s}$, is determined by a combination of contact microproperties, cohesion and friction. Thus,

$$
\left|\tau_{s}\right| \leq c+\sigma_{n} \tan \varphi=\tau_{s}^{\max } .
$$

Then:

$$
\Delta \tau_{s}=-k_{s} \Delta u_{s}^{e} .
$$

Or else, if

$$
\left|\tau_{\mathrm{s}}\right| \geq \tau_{s}^{\max },
$$


(a)

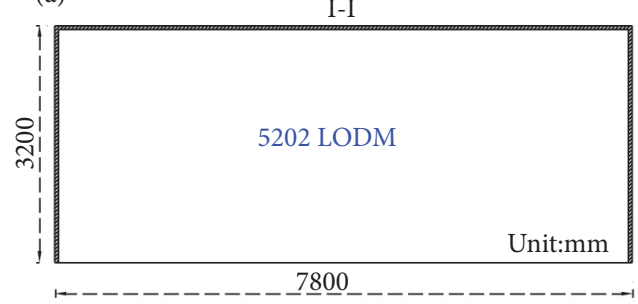

(b)

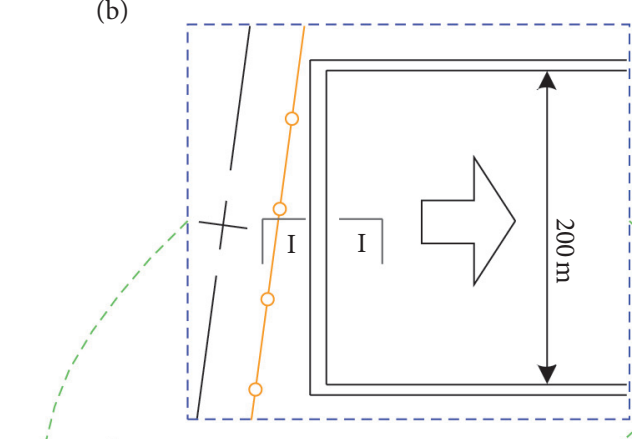

(c)

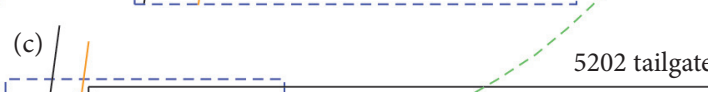$$
\begin{array}{r}
1 \\
1 \\
1 \\
1 \\
1 \\
1
\end{array}
$$$$
\text { to }
$$

1
+15
+1
1
1
1
1
0
1
1
1
1

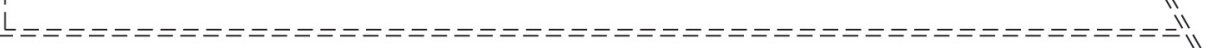

5204 working face

5206 working face

(d)
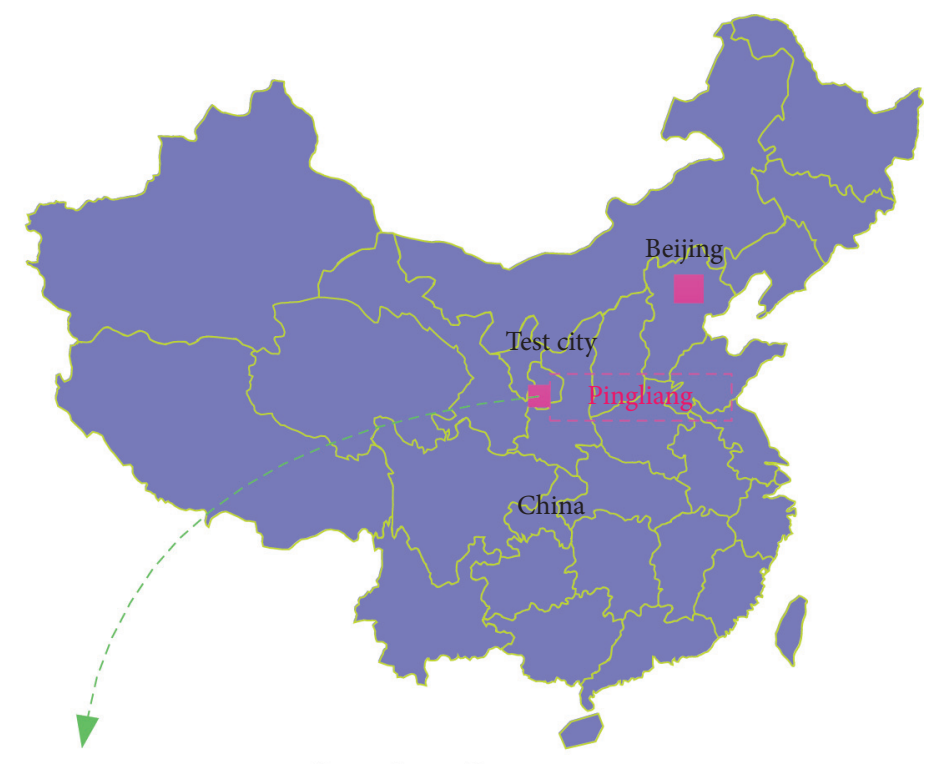


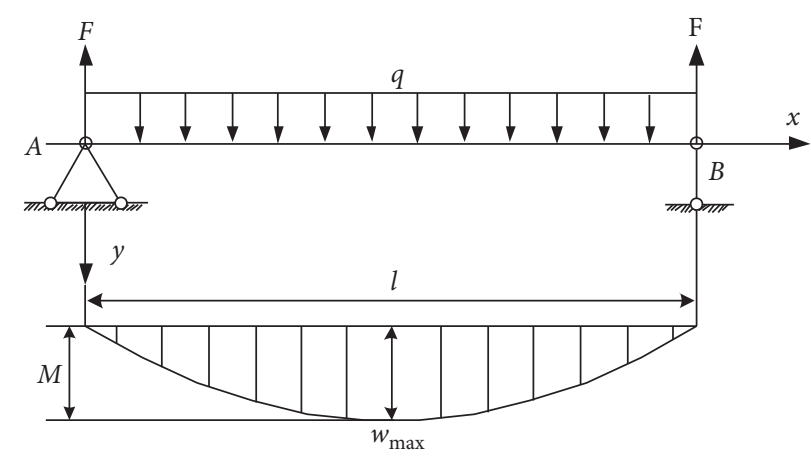

FIGURE 3: Mechanics model of simply supported beam in the LODM.

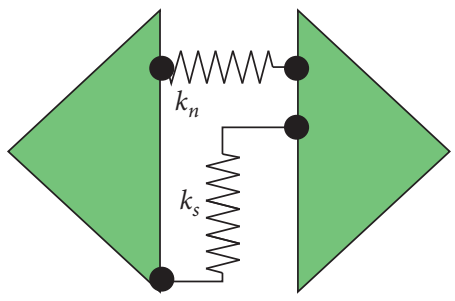

(a)

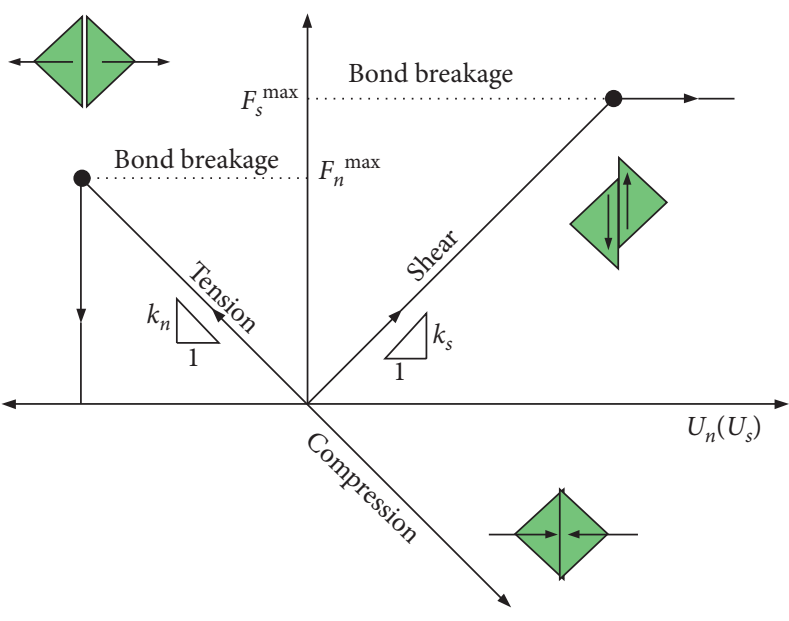

(b)

FIGURE 4: Using UDEC Trigon method to simulate the propagation process of rock mass fracture: (a) tangential and normal stiffness between blocks; (b) constitutive and failure behavior of tensile and shear strength between blocks.

then:

$$
\left|\tau_{\mathrm{s}}\right|=\operatorname{sign}\left(\Delta u_{\mathrm{s}}\right) \tau_{\max }
$$

where $c$ is the cohesion, $\varphi$ is the friction, and $\Delta u_{\mathrm{s}}^{e}$ is the elastic component of the incremental shear displacement, and $\Delta u_{s}$ is the total incremental shear displacement.

Micromechanical parameters, such as polygonal block and contact surface, jointly determine rock mechanical properties [32]. In UDEC Trigon model, the polygonal block is an elastic body, and four micromechanical parameters such as elastic modulus of polygonal block, internal friction angle $\varphi$, cohesion $C$, and tensile strength $T$ of contact surface should be determined for specific rocks.

3.1.2. Model Configuration. Two-dimensional UDEC model is established to simulate the failure mode of roof in the LODM and the effect analysis of supporting scheme. The numerical model is shown in Figure 5, with the width and the height of the model being, respectively, $70 \mathrm{~m}$ and $50 \mathrm{~m}$. In order to improve the calculation efficiency of the model, only the area of interest, i.e., the direct roof, is discretized by UDEC Trigon logic. The average size of triangular blocks in the study area is $0.2 \mathrm{~m}$. The thicker polygonal Voronoi blocks with average block size of $0.5 \mathrm{~m}$ were used. The thicker polygonal Voronoi blocks with average block sizes of $1.0 \mathrm{~m}$ and $2.0 \mathrm{~m}$ are used to simulate the coal measures strata at the boundary of the model.

At the bottom of the model and the boundary of both sides of the model, the displacement is fixed in the vertical and horizontal directions, respectively. According to the field measurement, the vertical stress is $19.3 \mathrm{MPa}$, the axis value that the maximum principal stress is erecting to the LODM is $23.2 \mathrm{MPa}$, and the axis value that the minimum principal stress is erecting to the LODM is $15.8 \mathrm{MPa}$. This in situ stress state is applied to the model, and the vertical stress of 19.3 MPa is applied to the upper boundary of the model to simulate the overlying rock pressure.

Generally speaking, the simulation calculation of the model of the LODM is divided into four steps. The first step is to apply in situ stress conditions to the global model for calculation. The second step is to simulate the excavation process of the LODM. In the second step, the excavation method of the LODM is tunneling in two times, that is, two times of excavation. The first time, the section with a width of $4.8 \mathrm{~m}$ and a height of $3.2 \mathrm{~m}$ is excavated, and the anchor 


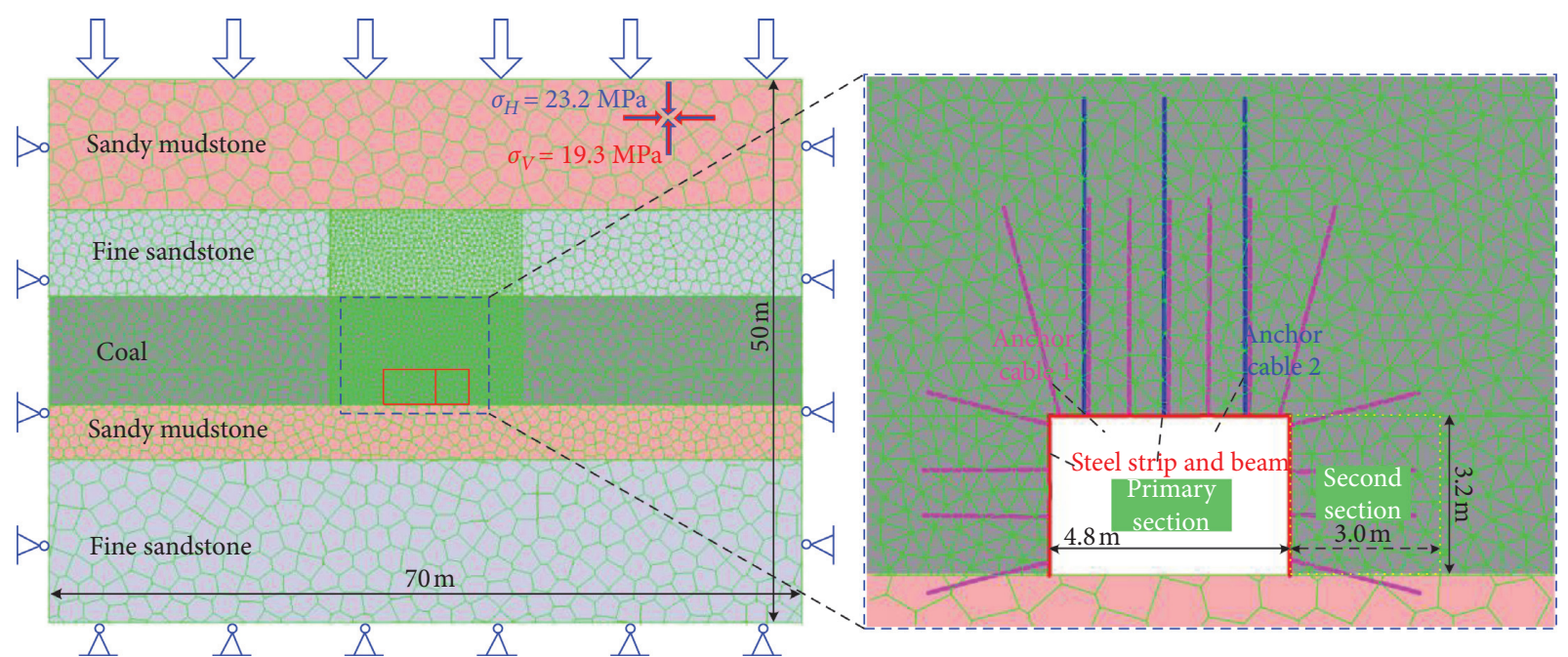

FIGURE 5: UDEC Trigon model of the LODM containing geometry and boundary conditions.

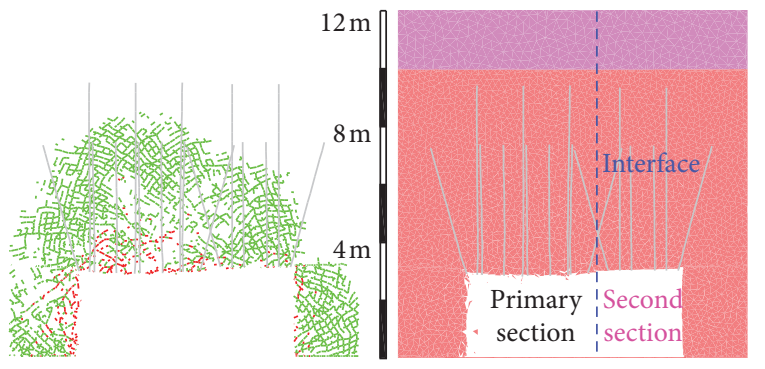

(a)

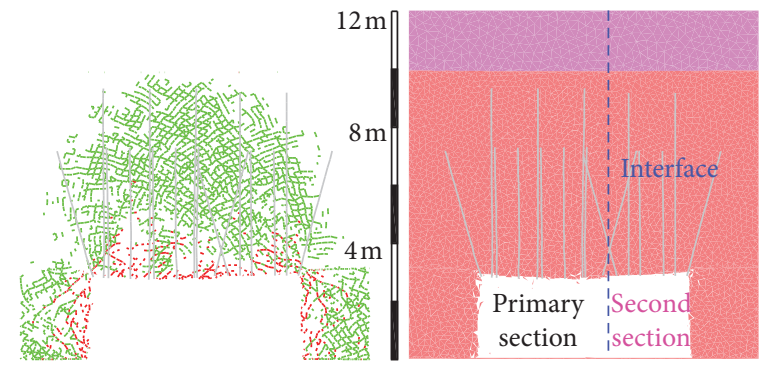

(b)

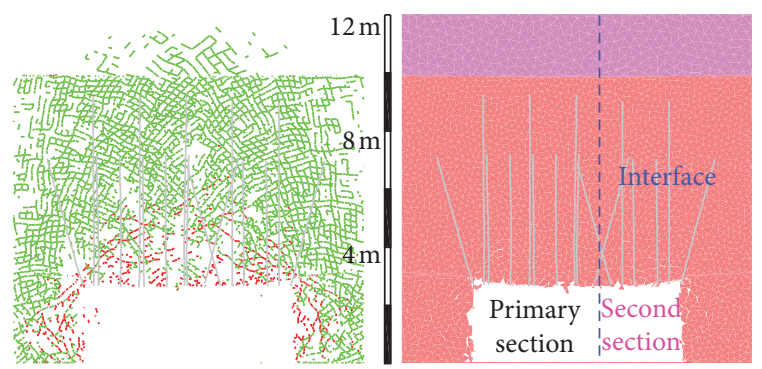

(c)

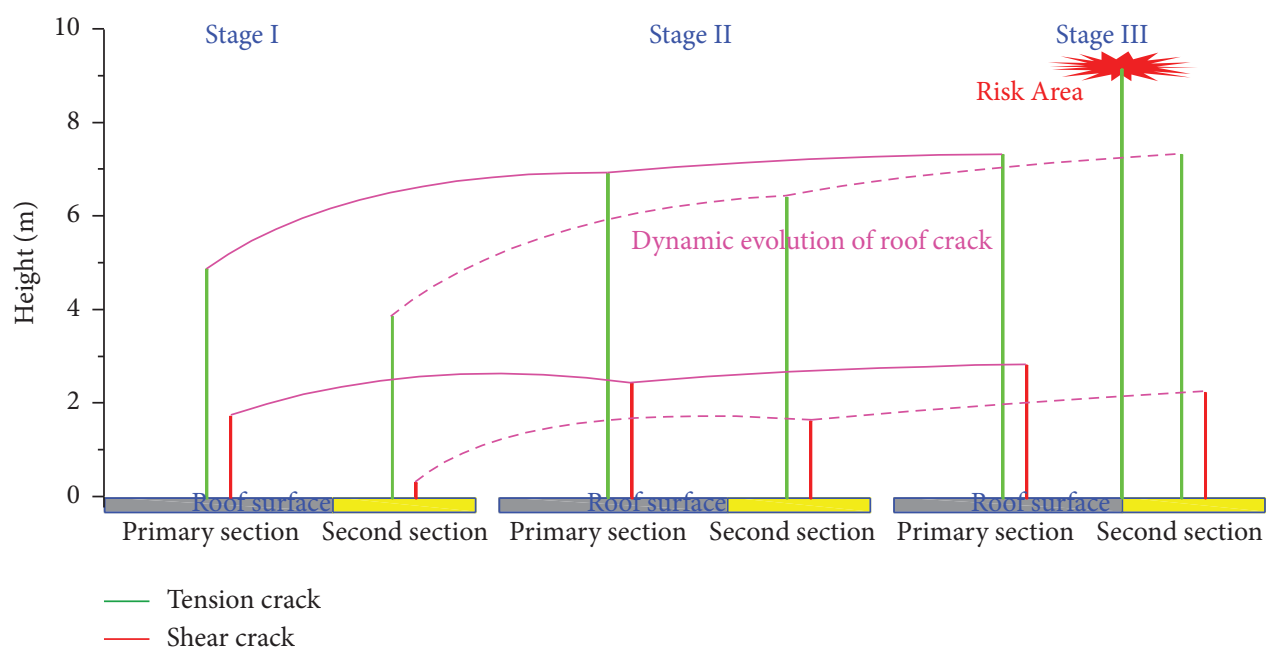

(d)

FIgURE 6: The development process of roof cracks in the full section and failure mode of roof: (a) Stage I; (b) Stage II; (c) Stage III; (d) dynamic evolution of roof crack after second excavation. (The green cracks represent tensile cracks, and the red cracks represent shear cracks.) 
cable support is carried out. The specific support parameters are shown in Figure 6, and then the calculation is carried out. In second time, the excavation distance will be to open-off cut with the designed section size. In the third step, after the excavation of the LODM, the simulation calculation is done under different supporting parameters. The analysis of the failure process of the roof and the supporting effect of different supporting strengths during the two excavations is helpful to determine the supporting time of two times tunneling of the LODM and the roof control strategy of the supporting strength.

3.2. Numerical Calibration. Rock properties obtained from laboratory should be converted into rock mass properties. $\mathrm{RQD}$ is widely used to estimate the deformation modulus of rock mass. Based on a large number of field monitoring data, Zhang and Einstein [36] established the relational expression between RQD and $E_{m} / E_{r}$ (3-6), so this relational expression was used to correct rock mass parameters. In our research, the RQD value of rock mass was observed by borehole camera:

$$
\frac{E_{m}}{E_{r}}=10^{0.0186 R Q D-1.91} .
$$

In the equation $E_{m}, E_{r}$ are the deformation modulus of rock mass and intact rock, respectively. Unconfined compressive strength (UCS) can be determined according to the ratio of $E_{m} / E_{r}$ [37]:

$$
\frac{\sigma_{m}}{\sigma_{r}}=\left(\frac{E_{m}}{E_{r}}\right)^{n} .
$$

$\sigma_{m}, \sigma_{r}$ are the strength of rock mass and intact rock, respectively. And the index $n$ for splitting, shearing, sliding, and rotation modes is $0.56,0.56,0.66$, and 0.72 , respectively. Since the failure process of roof is complicated seriously, there are many failure models. The value of index $n$ is 0.63 in this paper. Here, we also assume that the ratio of tensile strength $\left(T_{m}\right)$ of rock mass to tensile strength $\left(T_{r}\right)$ of intact rock follows the same relationship [37], so the properties of rock mass can be determined, and the results are listed in Table 1.

The rock mass property parameters of these data can not be directly applied to the model, and the mechanical parameters of the contact surface and polygon used to express the rock mass characteristics need to be obtained through numerical calibration. Therefore, UDEC Trigon logic correction models are established, which are UCS test block model with width of $2.0 \mathrm{~m}$ and height of $4.0 \mathrm{~m}$ and Brazilian disk test block model with diameter of $2.0 \mathrm{~m}$. The input parameters of block and contact surface are calibrated by trial and error method to match the rock mass properties given in Table 1. The calibration results of rock and coal are shown in Figure 7, and the microparameter is shown in Table 2. It can be seen from Table 3 that the error between the uniaxial compressive strength and elastic modulus obtained by numerical simulation and the data obtained by laboratory test is within $10 \%$. These parameters reproduce the rock mass properties in this study, so the micromechanical
TABLE 1: Intact rock properties and calculated rock mass properties.

\begin{tabular}{lccccccc}
\hline $\begin{array}{l}\text { Rock } \\
\text { strata }\end{array}$ & \multicolumn{3}{c}{ Intact rock } & RQD & \multicolumn{4}{c}{ Rock mass } \\
\hline $\begin{array}{l}\text { Sandy } \\
\text { mudstone }\end{array}$ & 5.89 & 11.44 & 1.14 & 90 & 3.42 & 8.12 & 0.81 \\
\hline $\begin{array}{l}\text { Fine } \\
\text { sandstone }\end{array}$ & 8.53 & 13.88 & 1.40 & 92 & 5.40 & 10.41 & 1.05 \\
\hline Coal & 1.48 & 4.99 & 0.50 & 88 & 0.79 & 3.36 & 0.34 \\
\hline
\end{tabular}

parameters of coal and rock mass determined in Table 2 are reasonable and usable.

3.3. Validation of the Global Model. In this section, the global model parameters are corrected for the primary section with a width of $4.8 \mathrm{~m}$ and a height of $3.2 \mathrm{~m}$. In the process of numerical simulation, the excavation of the LODM is simulated by deleting the blocks in the profile of primary section of the LODM. However, sudden excavation may lead to unbalanced response of the model, which will lead to dynamic stress paths around the excavation boundary. This dynamic stress usually produces a larger failure range around the excavation than expected [38]. In the field excavation, the open-off cut is gradually and continuously excavated by a heading machine, and the boundary of the LODM produces a static stress path $[39,40]$. In order to simulate this more realistic excavation effect, the FISH function is embedded into the UDEC model [35], and the equivalent force is decomposed into 10 stages to simulate the gradual excavation process. At each stage, the internal stress exerted on the excavation boundary is reduced by $10 \%$ of the original equivalent force, and enough numerical time step length is calculated to ensure the model reaches equilibrium. This method can minimize the impact of transient on material failure and provide a more static calculation scheme.

Adopting the abovementioned mechanical parameters of coal seam of the LODM and roof and floor rock in 5202 working face of Xin'an coal mine, and using the abovementioned "excavation" simulation method, the supporting parameters of primary excavated section are shown in Figure 5. Long and short anchor cables are both used for supporting. Short anchor cables with a diameter of $17.8 \mathrm{~mm}$ and a length of $4300 \mathrm{~mm}$ are used for basic support on the roof. The short anchor cables have a spacing of $800 \mathrm{~mm}$ and a row spacing of $800 \mathrm{~mm}$, while long anchor cables with a diameter of $17.8 \mathrm{~mm}$ and a length of $6300 \mathrm{~mm}$ are used for reinforcing support. The long anchor cables have a spacing of $1600 \mathrm{~mm}$ and a row spacing of $800 \mathrm{~mm}$. The two sides of the roadway are supported by anchor cables with a diameter of $17.8 \mathrm{~mm}$ and a length of $2700 \mathrm{~mm}$. The anchor cables of two sides of the roadway have a spacing of $800 \mathrm{~mm}$ and a row spacing of $800 \mathrm{~mm}$. The long and short anchor cables of the roof and the anchor cables of two sides of the roadway are made of reinforced ladder beam welded with round steel with a diameter of $14 \mathrm{~mm}$. The reinforced ladder beam used for short anchor cables on roof has a width of $60 \mathrm{~mm}$ and a 


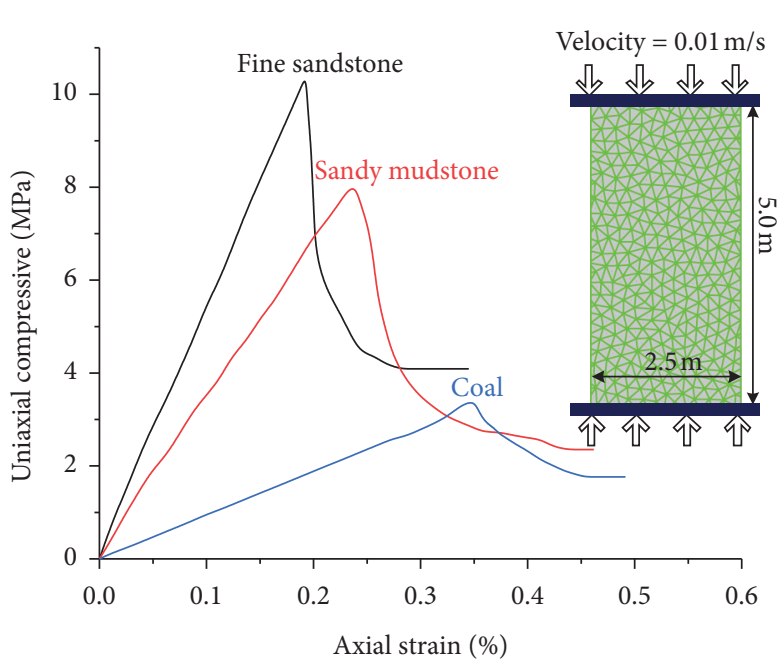

(a)

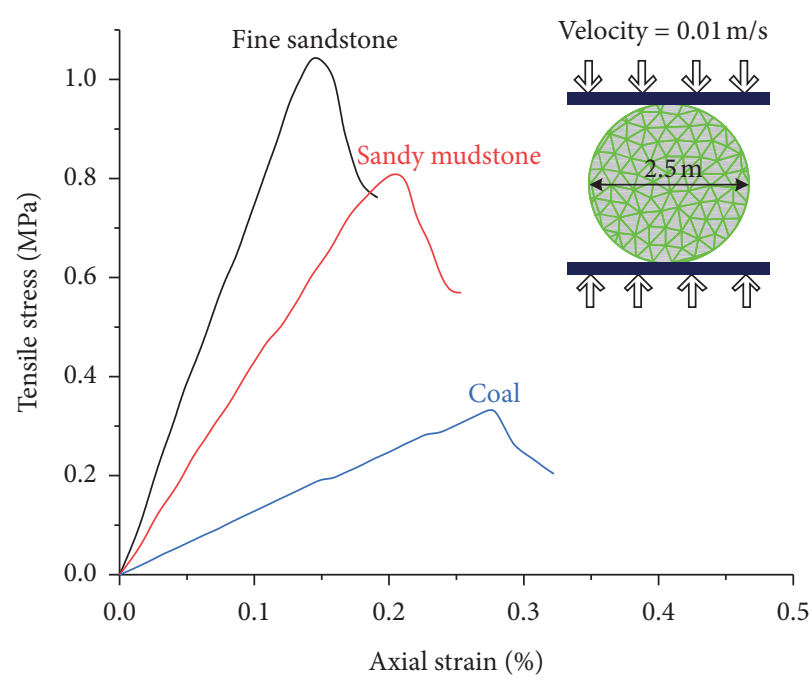

(b)

Figure 7: Calibration model using trigon logic: (a) calibrations for coal mass UCS; (b) Brazilian tensile test.

TABLE 2: Calibration of mechanical properties of rock strata and coal seams used in the model.

\begin{tabular}{lccccccc}
\hline \multirow{2}{*}{ Rock strata } & \multicolumn{3}{c}{ Matrix properties } & \multicolumn{4}{c}{ Contact properties } \\
& Density $\left(\mathrm{kg} / \mathrm{m}^{3}\right)$ & $E(\mathrm{GPa})$ & $k_{n}(\mathrm{GPa} / \mathrm{m})$ & $k_{s}(\mathrm{GPa} / \mathrm{m})$ & Cohesion $(\mathrm{MPa})$ & Friction angle $\left({ }^{\circ}\right)$ & Tensile strength $(\mathrm{MPa})$ \\
\hline Sandy mudstone & 2450 & 3.42 & 180 & 54.2 & 2.7 & 32 & 1.23 \\
Fine sandstone & 2550 & 5.40 & 278.5 & 83.6 & 3.4 & 35 & 1.59 \\
Coal & 1400 & 0.79 & 150.2 & 46.1 & 1.4 & 30 & 0.52 \\
\hline
\end{tabular}

TABLE 3: Comparison of theoretical and simulated values of elastic modulus, compressive strength, and tensile strength of rock mass.

\begin{tabular}{lccccccccc}
\hline \multirow{2}{*}{ Rock strata } & \multicolumn{2}{c}{$E(\mathrm{GPa})$} & \multirow{2}{*}{ Error (100\%) } & \multicolumn{2}{c}{ UCS (MPa) } & \multirow{2}{*}{ Error (100\%) } & \multicolumn{2}{c}{ BTS (MPa) } \\
& Target & Calibrated & & Target & Calibrated & & Target & Calibrated & Error (100\%) \\
\hline Sandy mudstone & 3.42 & 3.54 & 3.51 & 8.12 & 8.30 & 2.22 & 0.81 & 0.83 \\
Fine sandstone & 5.40 & 5.15 & -4.63 & 10.41 & 10.85 & 4.23 & 1.05 & 0.98 & -6.67 \\
Coal & 0.79 & 0.76 & -3.78 & 3.36 & 3.23 & 3.87 & 0.34 & 0.36 & 5.88 \\
\hline
\end{tabular}

length of $4500 \mathrm{~mm}$, while that used for long anchor cables on roof is $60 \mathrm{~mm}$ and $3300 \mathrm{~mm}$, respectively. The width and length of reinforced ladder beams used for the anchor cables on two sides of the roadway are $60 \mathrm{~mm}$ and $2500 \mathrm{~mm}$, respectively. In the numerical simulation, the built-in "cable" element is used to simulate the long and short anchor cables of the roof and the anchor cables of the two sides of roadway, and the built-in "liner" element is used to simulate the roof and the reinforced ladder beams of the two sides of roadway. The parameters of the supporting unit are shown in Table 4 in this paper.

The deformation of the primary excavation section of the LODM of 5202 working face is numerically simulated. Figure 8 shows the comparison between the numerical simulation results and the field monitoring deformation results. Although the time of numerical simulation is not the actual time of field measurement, UDEC Trigon model reproduces a deformation process of excavation section in horizontal and vertical directions. At the same time, the numerical simulation also reproduces the roof failure mode in the interface area of the two excavation sections after completion of the second section excavation, which will be studied in detail below. According to the results of numerical simulation, the maximum moved volume of the two sides of roadway of the primary excavation section is about $248 \mathrm{~mm}$, and the maximum moved volume of the roof and floor is about $410 \mathrm{~mm}$. The numerical calculation results are in good agreement with the field monitoring results, which verifies the rationality of UDEC Trigon model and the mechanical properties of rock mass used in this paper.

\section{Failure Mode of Roof in the LODM and Effect of Support Scheme}

4.1. Roof Failure Process and Support Timing of Primary Excavation Section. The fracture of roof rock can be identified by microseismic activity. In recent years, microseismic system has been used to better understand the failure process of roadway and working face. In UDEC Trigon model, the damage of block contact is considered as the main source of 
TABle 4: Properties of support elements used in the model.

\begin{tabular}{lcc}
\hline & Contact properties & Value \\
\hline \multirow{4}{*}{ Anchor cable } & Elastic modulus $(\mathrm{GPa})$ & 200 \\
& Tensile yield strength $(\mathrm{kN})$ & 380 \\
& Stiffness of the grout $(\mathrm{N} / \mathrm{m} / \mathrm{m})$ & $2 \mathrm{e} 9$ \\
& Cohesive capacity of the grout $(\mathrm{N} / \mathrm{m})$ & $4 \mathrm{e} 5$ \\
\hline \multirow{4}{*}{ Structure } & Elastic modulus $(\mathrm{GPa})$ & 200 \\
& Tensile yield strength $(\mathrm{MPa})$ & 500 \\
& Compressive yield strength $(\mathrm{MPa})$ & 500 \\
& Interface normal stiffness $(\mathrm{GPa} / \mathrm{m})$ & 10 \\
& Interface shear stiffness $(\mathrm{GPa} / \mathrm{m})$ & 10 \\
\hline
\end{tabular}

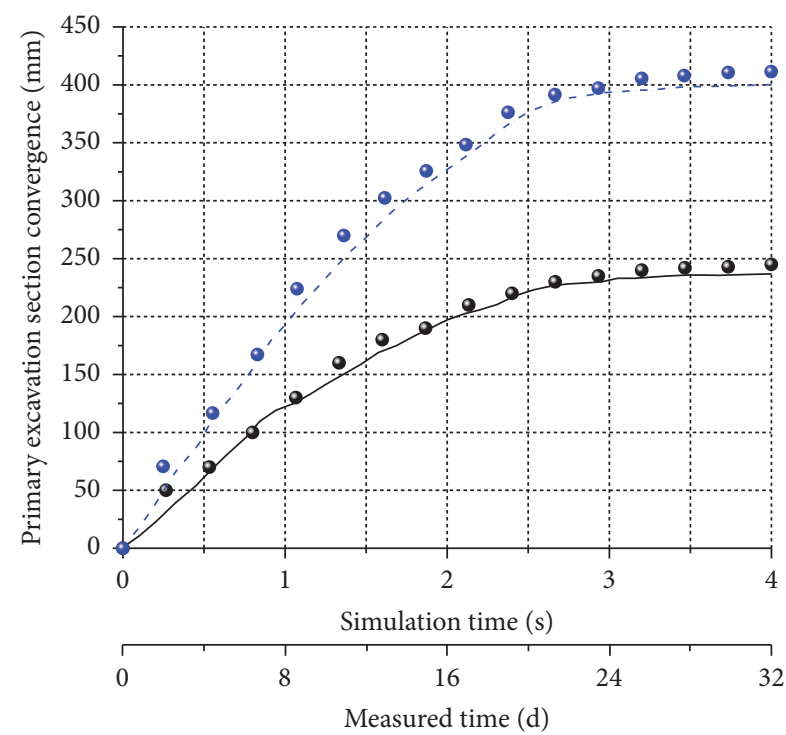

- Horizontal convergence (simulation)
- - Vertical convergence (simulation)
- Horizontal convergence (measured)
- Vertical convergence (measured)

Figure 8: Comparison between the simulation and measured primary excavation section convergence in the Xin'an coal mine.

microseisms, so the microseismic activity can be simulated by counting the number of crack increments in a specific calculation time [40, 41]. In this paper, the contact failure of roof is related to microseismic activity $[42,43]$. Therefore, the reasonable support timing can be determined through the development of microcracks.

Figure 9 shows the size of fracture and damage of roof in primary excavation section, and Figure 9 shows the height of fracture propagation and failure mode of roof in three different stages after primary section excavation. The term "damage" is defined as the ratio of the number of failure contacts (tensile strength or shear strength) to the number of all predefined contacts in the roof [34].

$$
D=\frac{L_{\mathrm{SH}}+L_{\mathrm{TE}}}{L_{\mathrm{TC}}} \times 100 \%,
$$

where $L_{\mathrm{SH}}$ is the total length of shear crack, $L_{\mathrm{TE}}$ is the total length of tensile crack, and $L_{\mathrm{TC}}$ is the total contact length.
It can be seen from Figures 9 and 10 that tensile fracture is the main mode leading to roof rock failure, and the process of roof rock failure and fracture propagation after primary excavation section is divided into three stages. In the first stage, the occurrence frequency of tensile cracks is 2.5 times that of shear cracks, the roof damage rapidly increases to $50 \%$, the height of tensile cracks on the roof expands to about $1.8 \mathrm{~m}$, and a small amount of shear cracks appears at the humeral angle of both sides of roadway in the primary excavation section. In the second stage, the occurrence frequency of tensile cracks and shear cracks on the roof gradually decreased, the damage of the roof slowly increased from $50 \%$ to $65 \%$, the height of tensile cracks on the roof expanded to about $4.0 \mathrm{~m}$, and the shear cracks at the humeral angle of the two sides of roadway gradually expanded to the central area of the roof, with the extension height of shear cracks about $1.5 \mathrm{~m}$. In the third stage, the occurrence frequency of tensile cracks and shear cracks on the roof tends to low stable value, and the roof damage also keeps stable from $65 \%$ to $68 \%$. The height of tensile cracks on the roof extends to about $4.8 \mathrm{~m}$, and the expanded height of shear cracks is about $1.7 \mathrm{~m}$, accompanied by a small amount of shear cracks in the deep part of the roof.

4.2. Failure Process and Support Timing of Full Section Roof after Secondary Excavation. The simulation method of secondary section excavation process is the same as that of primary section excavation process. The supporting parameters of secondary section excavation are shown in Figure 11(a). After the secondary section excavation, the failure mode and crack propagation process of roof of the full section open-off cut are shown in Figure 6. The development law of microcracks above the roof strata in the secondary section excavation process is similar to that in the primary section excavation process, so the development process of roof cracks in the secondary section excavation is also divided into three stages. It can be seen from Figure 6 that, in the first stage after secondary section excavation, the crack distribution of the full section roof is asymmetric, and the tensile crack propagation height of the primary section roof remains unchanged at $4.8 \mathrm{~m}$, the shear crack propagation height remains unchanged at $1.7 \mathrm{~m}$, the tensile crack propagation height of the secondary section roof reaches $3.8 \mathrm{~m}$, the shear crack appears near the humeral angle of the secondary excavation section, and a few shear cracks appear in the middle of the roof. In the second stage after secondary section excavation, affected by secondary section excavation, the development height of roof cracks in primary section increased. The propagation height of the tensile cracks on the roof of the primary excavation section increased from $4.8 \mathrm{~m}$ to $6.8 \mathrm{~m}$, while the propagation height of shear cracks increased from $1.7 \mathrm{~m}$ to $2.4 \mathrm{~m}$. The propagation height of tensile crack on the roof of the secondary excavation section increased from $3.8 \mathrm{~m}$ to $6.3 \mathrm{~m}$, and the propagation height of shear cracks increased from the humeral angle to $1.6 \mathrm{~m}$ above the roof of the secondary excavation section. In the third stage after the second section excavation, the crack propagation height of the full section roof continues to increase and tends to be stable, and the tensile crack height of the full section roof 


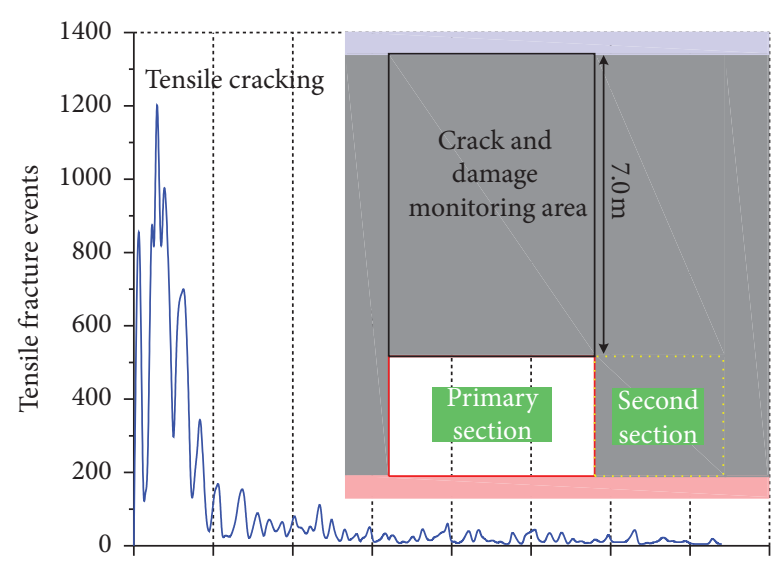

(a)

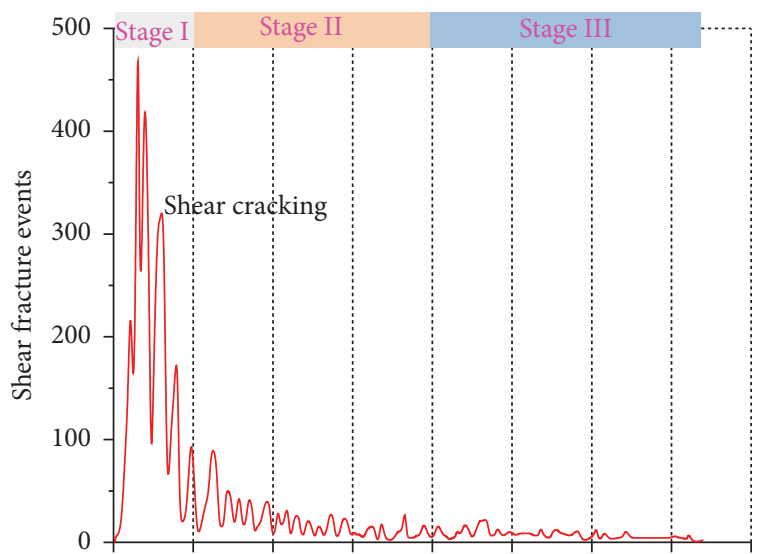

(b)

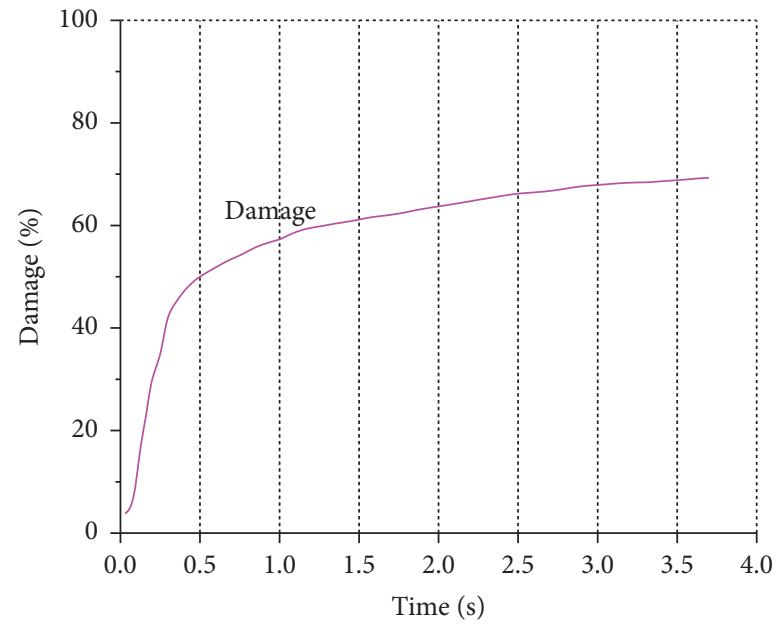

(c)

Figure 9: The change law of microcrack events and damage amount in the roof area after the primary section excavation.

extends to about $7.2 \mathrm{~m}$. Among them, the tensile crack height of the interface area of the two excavated sections even reaches about $9.0 \mathrm{~m}$. Compared with the previous two stages, the roof near the interface of the two excavated sections is seriously damaged, and the specific analysis is in Section 4.3.

Generally speaking, after the second section excavation, the failure mode of the full section roof is similar to that of the primary excavation section, which is mainly manifested in that the last two stages are accompanied by the deep expansion of roof cracks, and the tensile and shear cracks are changed from microcracks in the first stage to macrocracks in the last two stages. At the same time, along with the second section excavation, the cracks above the roof of the first excavation section are gradually transferred to the deep. In the full section, the failure mode of the roof mainly shows that the macrocracks of the roof in the interface area of the two excavations increase and extend to the deep. Therefore, after the second section excavation, the reasonable support timing should be chosen before the second stage, and the key control of the roof strata in the interface area of the second excavation must be considered.

\subsection{Analysis of Supporting Effect of the LODM}

4.3.1. Three Schemes for Roof Support. Anchor rod and anchor cable support is the main method of rock stratum control in roadway roof. The main functions of pretension anchor cable are divided into two aspects: on the one hand, the anchor cable installed in the rock stratum can reinforce the strength of rock mass, limit the deformation of rock mass within the range of anchor cable action, and limit the sliding of preexisting microcracks in the roof rock mass. On the other hand, the support provided by the reinforced ladder beam, pallet, and steel mesh installed with anchor cable and the pretension exerted on anchor cable can provide constraint on the roof rock stratum surface through the extension of reinforced ladder beam, pallet, and steel mesh. Therefore, three schemes for roof support are proposed for the open-off cut of 5202 working face in Xin'an coal mine (see in Figure 11). Among the three support schemes, the support parameters of primary section are unchanged, and the support parameters of primary section and three support schemes for secondary section are as follows. 


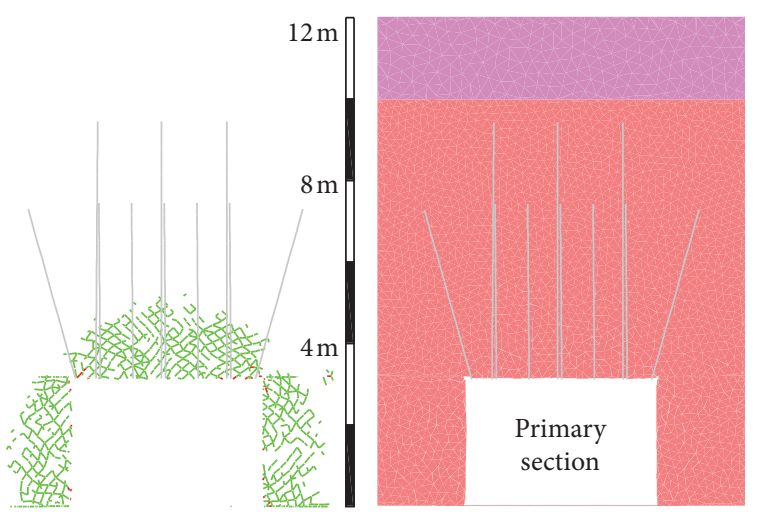

(a)

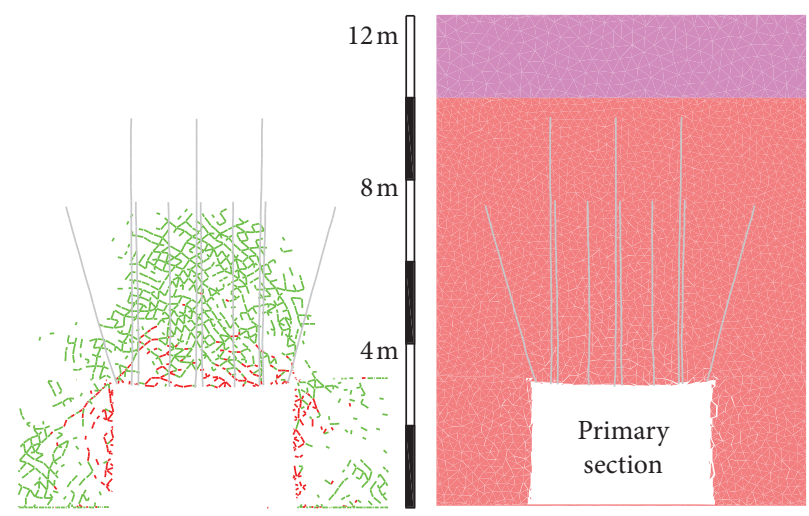

(b)

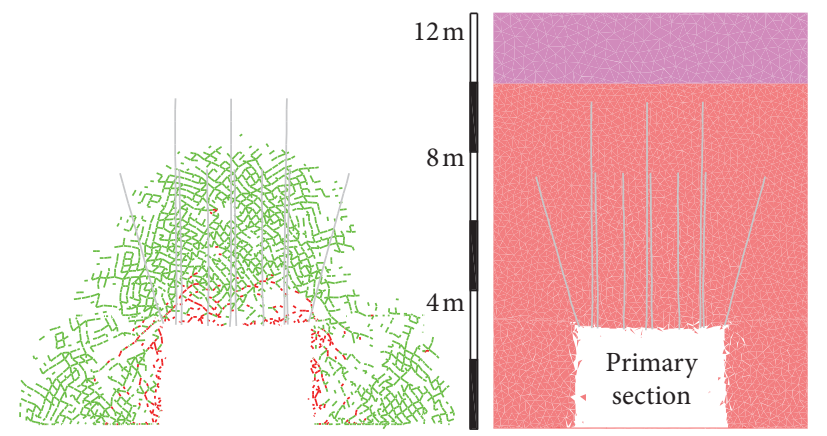

(c)

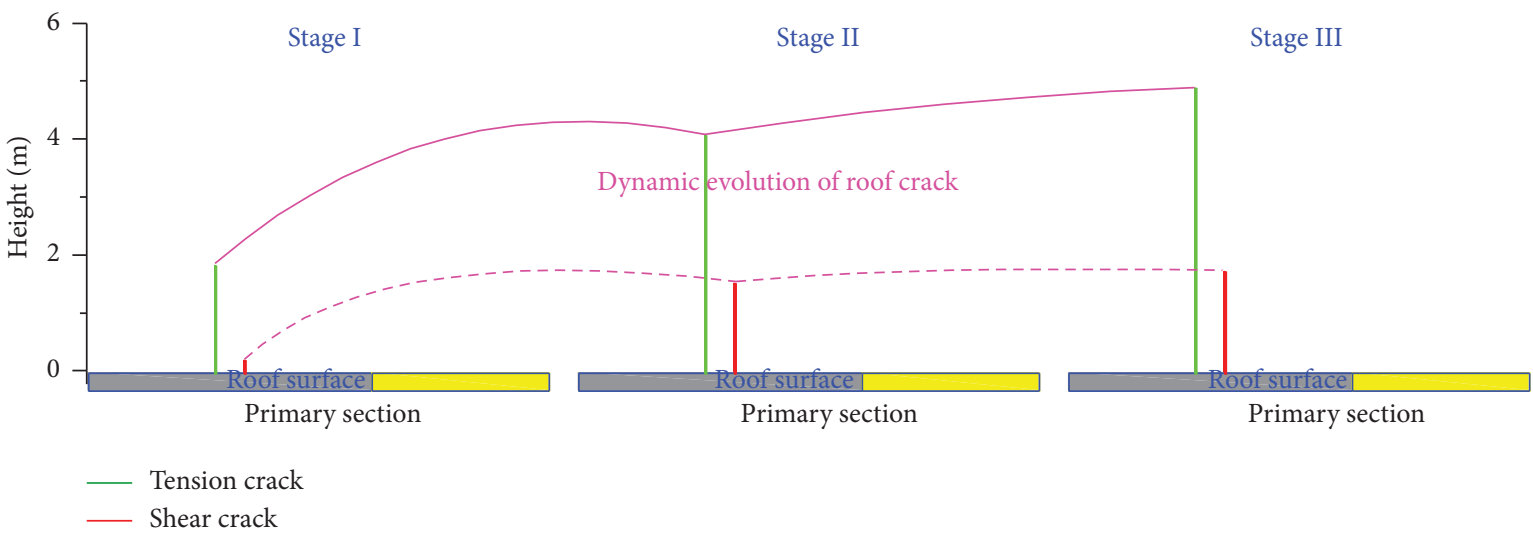

(d)

FIGURE 10: Crack development process and roof failure mode after primary excavation section supporting: (a) Stage I; (b) Stage II; (c) Stage III; (d) dynamic evolution of roof crack after primary excavation (green cracks represent tensile cracks, and the red cracks represent shear cracks).

4.3.2. Failure Characteristics of Full Section Roof. Scheme 1 is used in the simulation of roof failure process in Section 4.2. So in this section, the same UDEC Trigon model and simulation process are used to simulate Scheme 2 and Scheme 3. Figure 12 shows the variation law of cracks, damage, and failure modes of roof strata in the LODM under three kinds of support. In order to show the damage degree of roof in different areas above the roof more clearly, the rock strata within $9 \mathrm{~m}$ above the roof of full section open-off cut are divided into $1 \mathrm{~m} \times 1 \mathrm{~m}$ square grids. The damage calculation of each subgrid is calculated according to Formula (14)

\section{Discussion}

5.1. Support Timing and Key Points of Control. According to the analysis of roof failure mode, crack distribution, and damage characteristics of the LODM, the following measures are put forward about roof support timing and key points of control. 


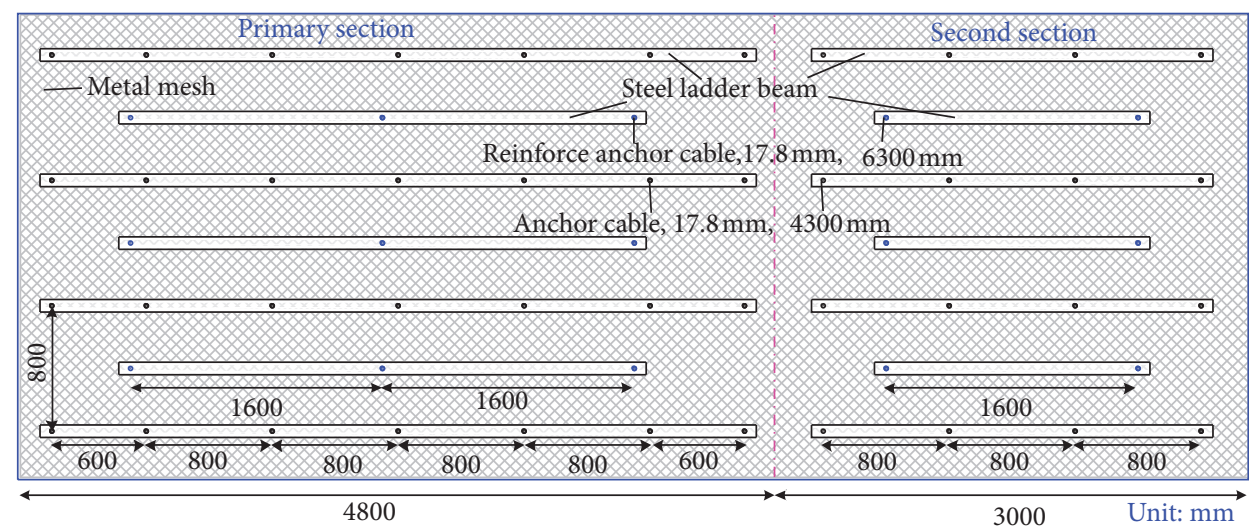

(a)

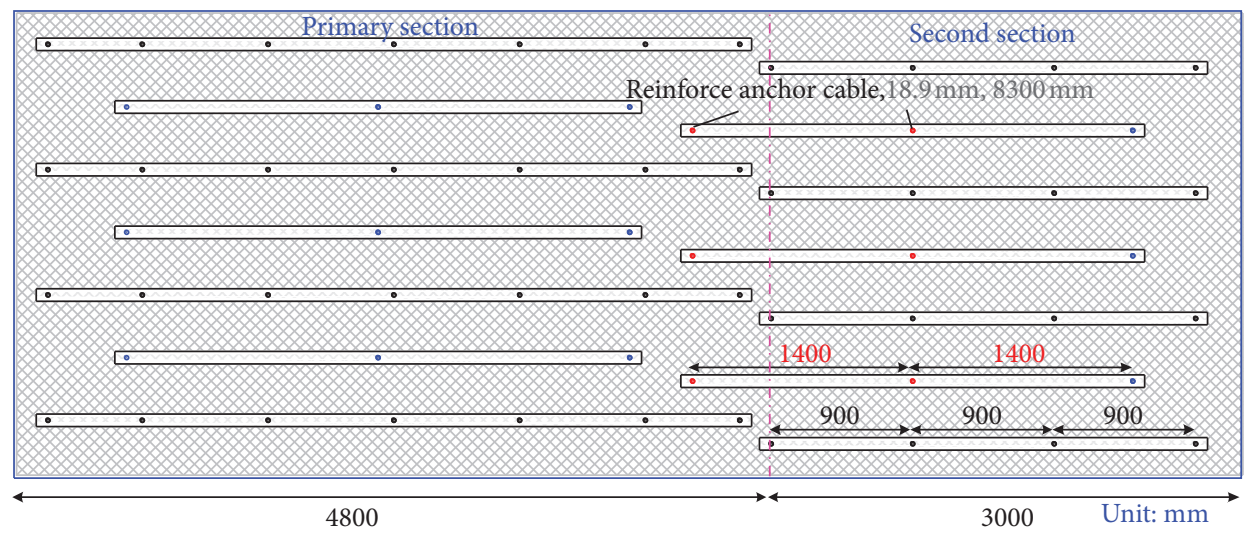

(b)

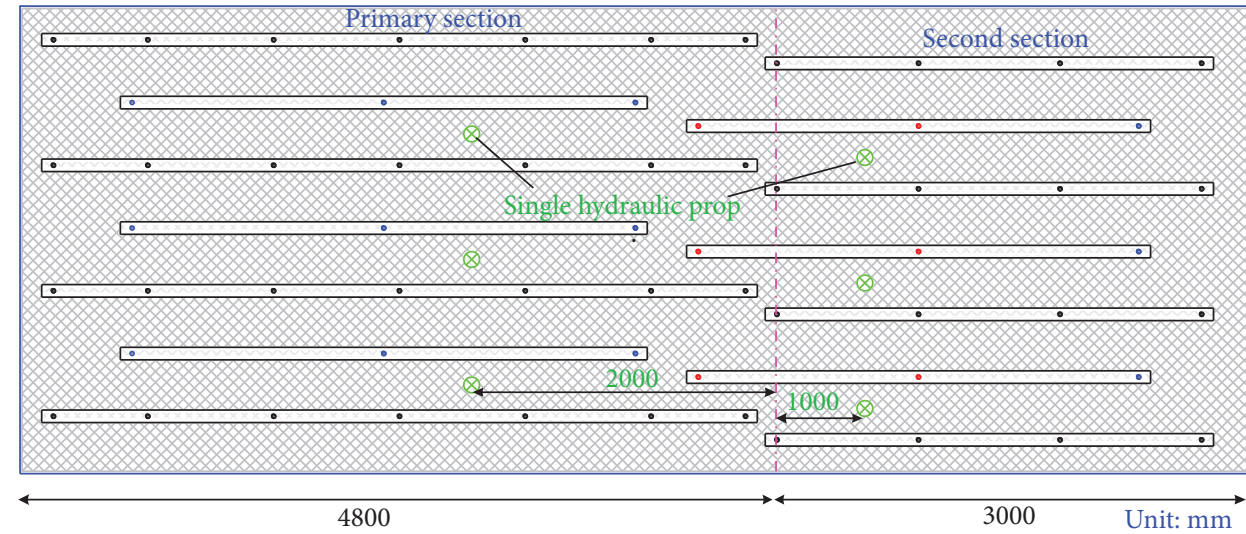

(c)

Figure 11: Plan view of three roof support schemes, (a) Scheme 1; (b) Scheme 2; (c) Scheme 3.

(1) Excavation and open-off cut are the way of the two times tunneling. The primary excavation section should be supported in time. Before the second section excavation, in addition to the conventional long and short anchor cable support, a row of single hydraulic prop is installed in the primary excavation section together with the hinged top beam to actively bear and support the roof, ensuring the support strength of the primary excavation section.

(2) After secondary section excavation, the roof should be supported in time, and the reinforcing long anchor cable should be installed in time after installing the short anchor cable. The interface area of the two excavation sections should be reinforced and supported to ensure the stability of roof strata in the interface area.

(3) The high pretension anchor cable supports the roof with high-strength surface protection components such as reinforcing mesh, reinforced ladder beam, and pallet, controls the expansion of cracks on the surface and deep part of the roof, and improves the active support effect. 

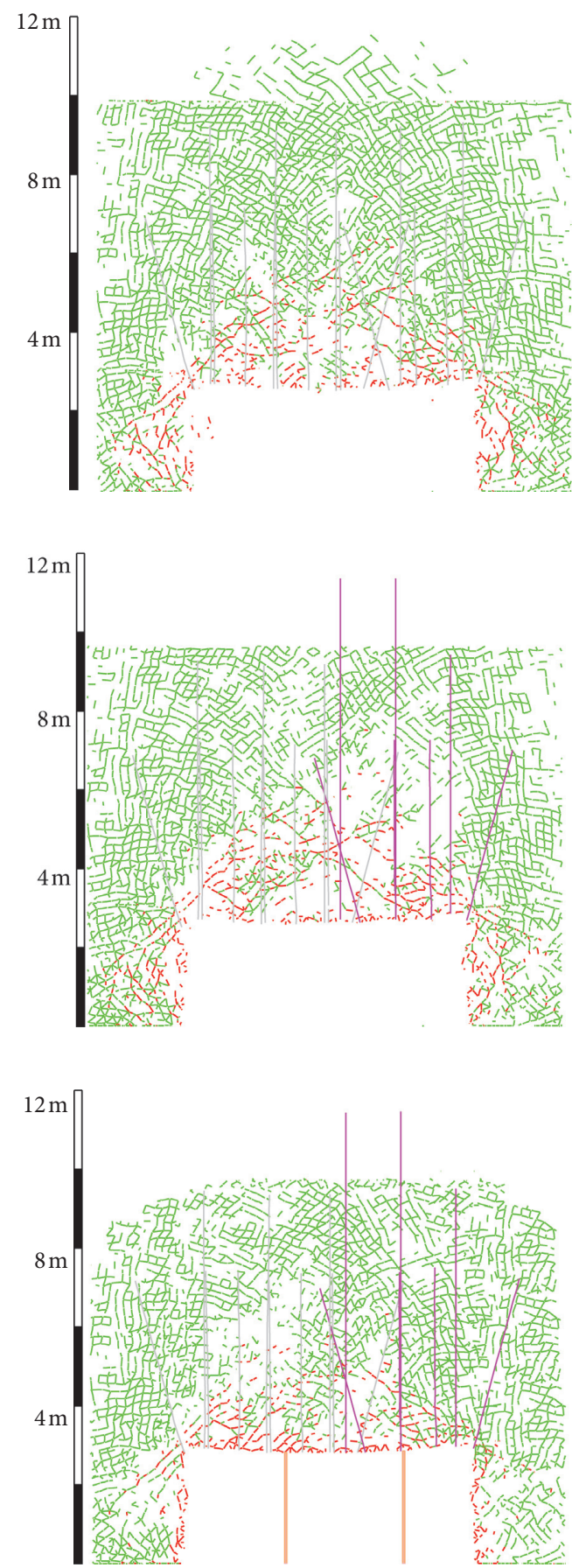
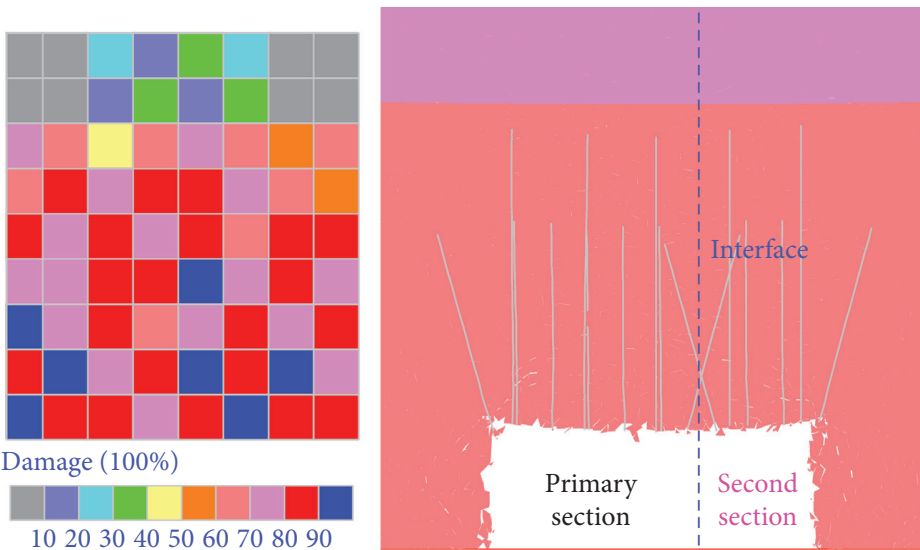

(a)
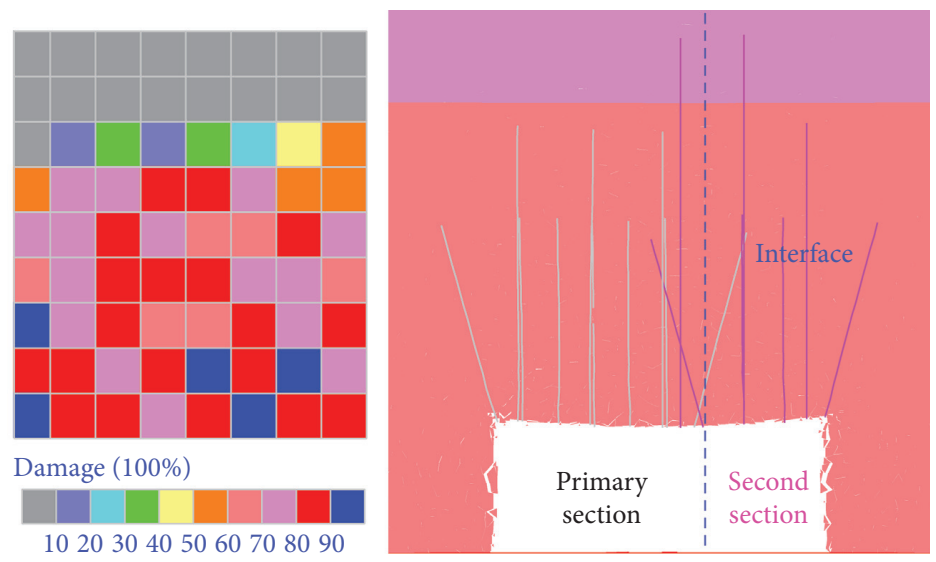

(b)
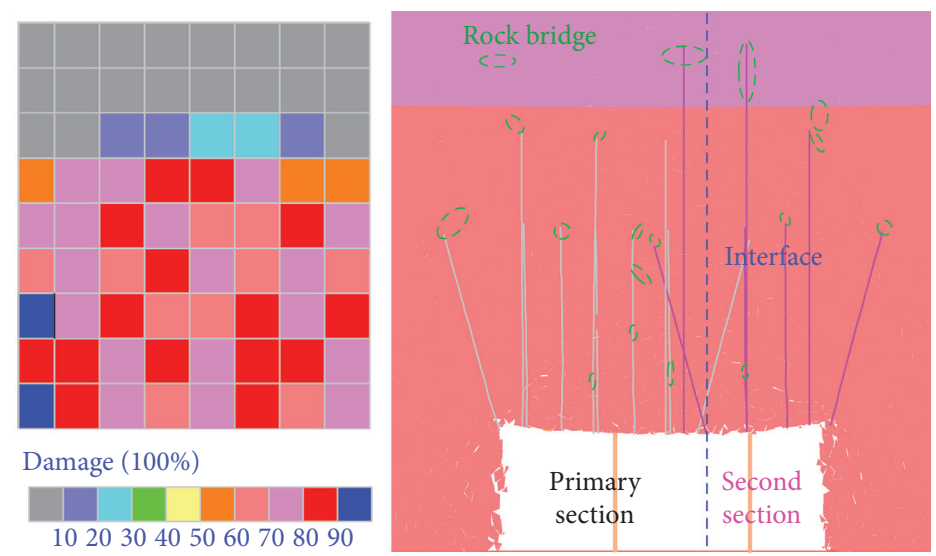

(c)

FIGURE 12: Distribution, damage, and failure modes of roof cracks in three support schemes, (a) Scheme 1; (b) Scheme 2; (c) Scheme 3. (The green cracks represent tensile cracks, and the red cracks represent shear cracks.)

5.2. Control Technical Parameters. After primary section excavation, the roof is supported by short anchor cables with a diameter of $17.8 \mathrm{~mm}$ and a length of $4300 \mathrm{~mm}$, with a spacing of $800 \mathrm{~mm}$ and a row spacing of $800 \mathrm{~mm}$, and reinforced by long anchor cables with a diameter of $17.8 \mathrm{~mm}$ and a length of $6300 \mathrm{~mm}$, with a spacing of $1600 \mathrm{~mm}$ and a row spacing of $800 \mathrm{~mm}$. Before the secondary section excavation, a row of DW-250/100 single hydraulic prop with working resistance of $250 \mathrm{kN}$ is arranged at $2000 \mathrm{~mm}$ away from the interface of the two excavation sections to match with DJB-1000 metal hinged roof beam. After secondary section excavation, the roof is supported by short anchor cables with a diameter of $17.8 \mathrm{~mm}$ and a length of $4300 \mathrm{~mm}$, with a spacing of $900 \mathrm{~mm}$ and a row spacing of $800 \mathrm{~mm}$. The two sides of roadway are supported by anchor cables with a diameter of $17.8 \mathrm{~mm}$ and a length of $2700 \mathrm{~mm}$. Long anchor 


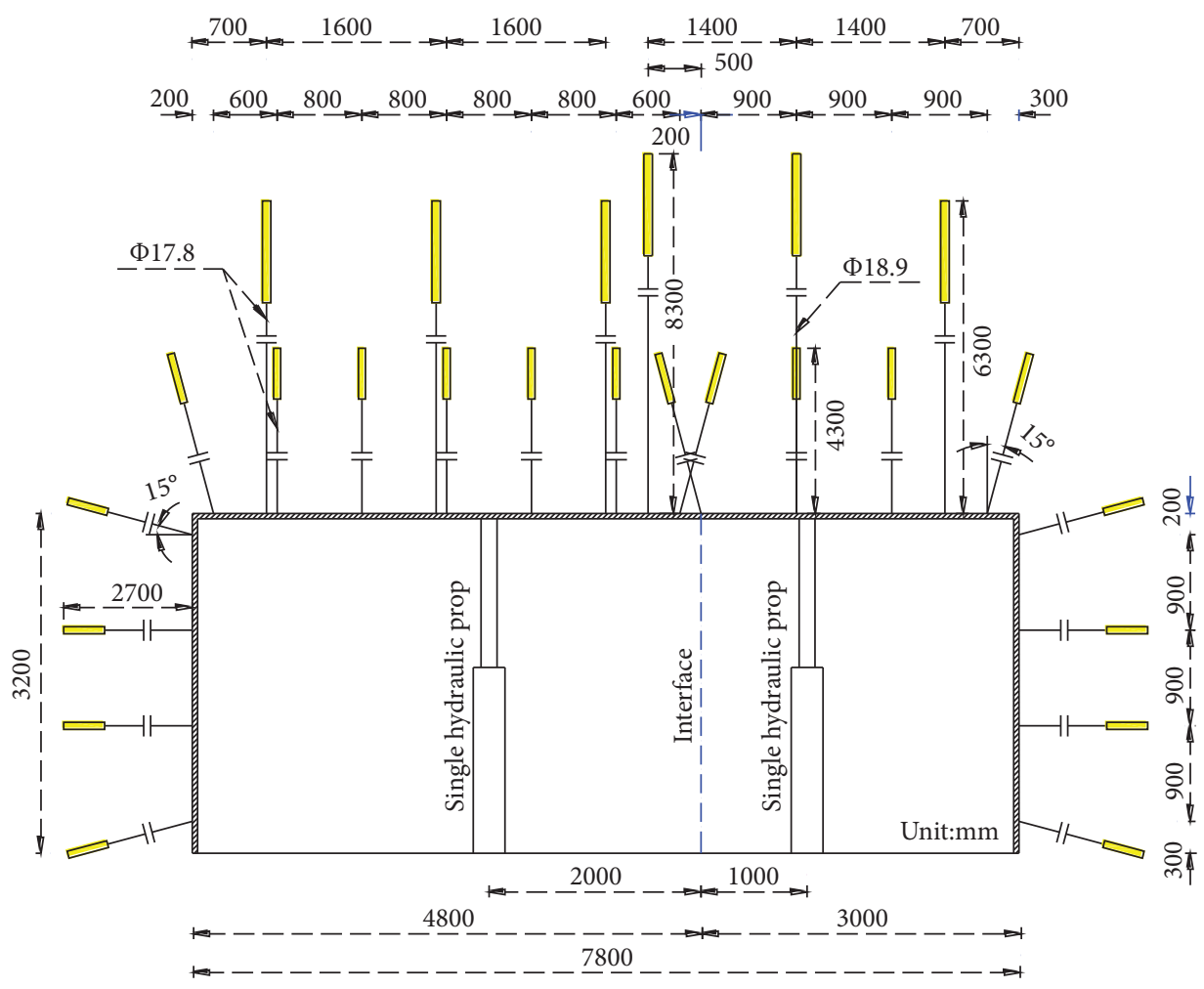

FIgURE 13: Parameter diagram of the LODM support in 5202 working face.

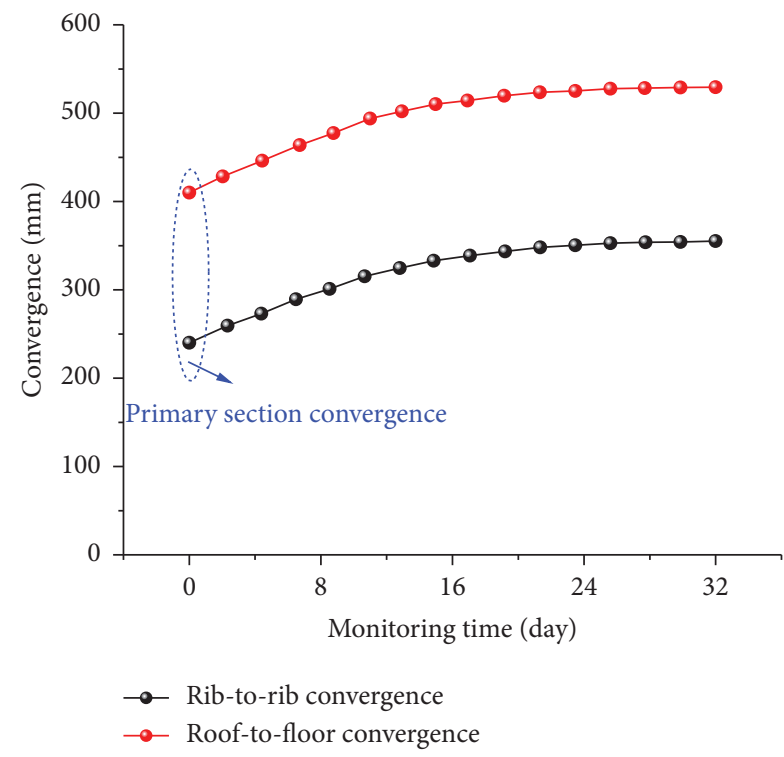

FIGURE 14: Field monitoring diagram of the LODM deformation of 5202 working face.

cables with a diameter of $18.9 / 17.8 \mathrm{~mm}$ and a length of $8300 /$ $6300 \mathrm{~mm}$ are used for reinforcement support, with a spacing of $1400 \mathrm{~mm}$ and a row spacing of $800 \mathrm{~mm}$. Short anchor cables with a diameter of $17.8 \mathrm{~mm}$ and a length of $2700 \mathrm{~mm}$ are used on the two sides of roadway to support the two sides of roadway. The anchor cable spacing is $900 \mathrm{~mm}$ and the row spacing is $800 \mathrm{~mm}$, and the pretension of both long and short anchor cables is $250 \mathrm{kN}$. The supporting parameters of long and short anchor cables in the full section are shown in Figure 13.

5.3. Field Test of Roof Support Effect. After adopting the above optimized support scheme of the LODM, the roof deformation of the two excavation sections of the roof of 5202 open-off cut is shown in Figure 14. The monitoring results show that the deformation of the roof strata of the 5202 open-off cut is effectively controlled, the deformation of the roof of the two excavation sections is stable for a period of time, and the convergence deformation of the roof-to-floor and the rib-to-rib of the LODM is $550 \mathrm{~mm}$ and $350 \mathrm{~mm}$, respectively. The field application shows that the surrounding rock of roof has been effectively improved under the action of support of high-strength long and short anchor cable and bearing structure of high working resistance hydraulic prop.

\section{Conclusions}

In order to solve the stability control problem of surrounding rock in the LODM, this paper systematically studies the evolution law of roof crack evolution, failure mode, and damage degree in secondary tunneling of the LODM by means of field investigation, theoretical calculation, numerical simulation, and engineering practice, compares and analyzes the control effect of roof crack and damage under three supporting conditions, and determines 
the reasonable support timing and control technical parameters. The main conclusions are as follows.

(1) The mechanical model of roof deformation of the LODM is established, and it is determined that the deflection of roof is directly proportional to the cubic of span. The secondary tunneling excavation method is selected for the LODM, so as to avoid large deflection deformation and instability of roof caused by primary excavation full section open-off cut.

(2) A UDEC Trigon model is established to simulate the evolution characteristics, failure modes, and damage degree of roof cracks in secondary tunneling of the LODM, the input parameters are calibrated, the global model is verified according to the monitoring data, and the failure process of roof rocks in the LODM is studied. According to the microseismic activity of cracks in the simulation process, the failure process of roof rock stratum in the LODM is divided into three stages, and the reasonable support timing is determined.

(3) The limiting effects of the three supporting schemes on the crack evolution of roof strata are evaluated, and the results show that the key supporting in the interface area can reduce the crack propagation height of roof strata in secondary tunneling and weaken the damage degree of roof strata in the deep.

(4) The control timing and key points of control for surrounding rock of the LODM are put forward, and the technical parameters of the LODM in 5202 working face in Xin'an Coal Industry are determined. The field test shows that, after reinforcing and supporting by the lengthened anchor cable and single hydraulic props, the moved volumes of the LODM of rib-to-rib and roof-to-floor are about $350 \mathrm{~mm}$ and $550 \mathrm{~mm}$, respectively. The results provide a basis for the control of surrounding rock of the LODM under similar conditions.

\section{Data Availability}

The data used to support the findings of this study are available from the corresponding author upon request.

\section{Conflicts of Interest}

The authors declare no conflicts of interest.

\section{Authors' Contributions}

Conceptualization was performed by Shuaigang Liu, Yanhui $\mathrm{Li}$, and Jianbiao Bai; methodology was developed by Xiangyu Wang; formal analysis and investigation were performed by Shuaigang Liu and Xiangyu Wang; software was provided by Shuaigang Liu; validation was performed by Bowen $\mathrm{Wu}$ and Guanghui Wang; reviewing and editing were performed by Shuaigang Liu, Jianbiao Bai, Xiangyu Wang, Bowen Wu, Guanghui Wang, Yanhui Li, and Jun Xu.

\section{Acknowledgments}

This research was financially supported by the National Natural Science Foundation of China through contract no. 52074239. The authors thank Xin'an coal mine for their support during the field work.

\section{References}

[1] H. Xie, Y. Ju, S. Ren, F. Gao, J. Liu, and Y. Zhu, "Theoretical and technological exploration of deep in situ fluidized coal mining," Frontiers in Energy, vol. 13, no. 4, pp. 603-611, 2019.

[2] J. Chen, J. Zhao, S. Zhang et al., "An experimental and analytical research on the evolution of mining cracks in deep floor rock mass," Pure and Applied Geophysics, vol. 177, no. 11, pp. 5325-5348, 2020.

[3] S. Shreedharan and P. H. S. W. Kulatilake, "Discontinuumequivalent continuum analysis of the stability of tunnels in a deep coal mine using the distinct element method," Rock Mechanics and Rock Engineering, vol. 49, no. 5, pp. 1903-1922, 2016.

[4] K. Wang, L. Wang, B. Ren, and H. Fan, "Understanding the effect of cementitious grouting pressure on micro-fracture permeability for rock reinforcement underground: a lab study," Energies, vol. 13, no. 16, p. 4225, 2020.

[5] Z. Zhang, J. Bai, Y. Chen, and S. Yan, "An innovative approach for gob-side entry retaining in highly gassy fullymechanized long wall top-coal caving," International Journal of Rock Mechanics and Mining Sciences, vol. 80, pp. 1-11, 2015.

[6] D. Zhu, Y. Wu, Z. Liu, X. Dong, and J. Yu, "Failure mechanism and safety control strategy for laminated roof of widespan roadway," Engineering Failure Analysis, vol. 111, Article ID 104489, 2020.

[7] G. Li, F. Ma, J. Guo, H. Zhao, and G. Liu, "Study on deformation failure mechanism and support technology of deep soft rock roadway," Engineering Geology, vol. 264, Article ID 105262, 2020.

[8] J. G. Kan, N. Zhang, G. C. Li, W. Cheng, and D. H. Zhang, "Analysis of excavation method of large span open-off cut in deep mine," Journal of Mining and Safety Engineering, vol. 26, pp. 41-45, 2009, in Chinese.

[9] Y. Yu, J. Bai, K. Chen, X. Wang, T. Xiao, and Y. Chen, "Failure mechanism and stability control technology of rock surrounding a roadway in complex stress conditions," Mining Science and Technology (China), vol. 21, no. 3, pp. 301-306, 2011.

[10] Y. Hu, Y. Liu, and L. Shi, "Research on supporting technology for surrounding rock of inclined large-span open-off cut roadway," Geotechnical and Geological Engineering, vol. 38, no. 2, pp. 1873-1884, 2020.

[11] G. M. Chi, L. H. Zhang, and H. J. Tang, "Comprehensive control technology of ultra large section open-off cut surrounding rock," Coal Science and Technology, vol. 11, pp. 27-31, 2017, in Chinese.

[12] Z. Z. Zhang, M. Deng, B. J. Bai, S. Yan, and X. Y. Yu, "Stability control of gob-side entry retained under the gob with close distance coal seams," International Journal of Mining Science and Technology, vol. 31, no. 2, pp. 321-332, 2020.

[13] D. P. Yin, "Study on surrounding rock control and support system in a super large section roadway with thick fragmentation coal seam" Ph.D. thesis, China University of Mining and Technology. Beijing, China, 2011, in Chinese.

[14] S. L. Zhang, "Study on bolt-net supporting technology of thick seam and large-section cut in Wangjialing coal mine," 
M. A. thesis, China University mining and technology, Xuzhou, China, 2015, in Chinese.

[15] F. L. He, L. Xu, H. K. Wu, and Y. F. Wang, "Fracture field evolution and stability analysis of surrounding rock in thick coal roof large-section," Journal of China Coal Society, vol. 39, no. 2, pp. 336-346, 2014, in Chinese.

[16] S. Xie, Q. Zhang, D. Chen et al., "Research of roof anchorage rock beam bearing structure model of extra-large width openoff cut and its engineering application in a coal mine, China," Advances in Civil Engineering, vol. 2020, Article ID 3093294, 19 pages, 2020.

[17] W.-q. Peng, H. Zhu, Q. Wang, and G. Peng, "Study on safety control of large-section roadway with high stress and broken surrounding rock," Advances in Civil Engineering, vol. 2021, Article ID 6686208, 12 pages, 2021.

[18] G.-c. Zhang, F.-l. He, Y.-h. Lai, and H.-g. Jia, "Ground stability of underground gateroad with $1 \mathrm{~km}$ burial depth: a case study from Xingdong coal mine, China," Journal of Central South University, vol. 25, no. 6, pp. 1386-1398, 2018.

[19] Z. Zhang, M. Deng, X. Wang, W. Yu, F. Zhang, and V. D. Dao, "Field and numerical investigations on the lower coal seam entry failure analysis under the remnant pillar," Engineering Failure Analysis, vol. 115, Article ID 104638, 2020.

[20] S. Liu, J. Bai, X. Wang, B. Wu, and W. Wu, "Mechanisms of floor heave in roadways adjacent to a goaf caused by the fracturing of a competent roof and controlling technology," Shock and Vibration, vol. 2020, Article ID 5632943, 17 pages, 2020.

[21] Z. Zhang, M. Deng, J. Bai, X. Yu, Q. Wu, and L. Jiang, "Strain energy evolution and conversion under triaxial unloading confining pressure tests due to gob-side entry retained," International Journal of Rock Mechanics and Mining Sciences, vol. 126, Article ID 104184, 2020.

[22] N. Meng, Y. Chen, J. Bai, X. Wang, W. Wu, and B. Wu, "Numerical simulation of directional fracturing by shaped charge blasting," Energy Science \& Engineering, vol. 8, no. 5, pp. 1824-1839, 2020.

[23] S. Wang, W. Xu, M. Sun, and W. Wang, "Experimental investigation of the mechanical properties of fine-grained sandstone in the triaxial cyclic loading test," Environmental Earth Sciences, vol. 78, no. 14, 2019.

[24] J. Chen, H. Zhao, F. He, J. Zhang, and K. Tao, "Studying the performance of fully encapsulated rock bolts with modified structural elements," International Journal of Coal Science \& Technology, vol. 8, no. 1, p. 64, 2021.

[25] J. Yang and M. Fall, "Coupled hydro-mechanical modelling of dilatancy controlled gas flow and gas induced fracturing in saturated claystone," International Journal of Rock Mechanics and Mining Sciences, vol. 138, Article ID 104584, 2021.

[26] B. Wu, X. Wang, J. Bai, W. Wu, X. Zhu, and G. Li, "Study on crack evolution mechanism of roadside backfill body in gob-side entry retaining based on UDEC trigon model," Rock Mechanics and Rock Engineering, vol. 52, no. 9, pp. 3385-3399, 2019.

[27] Q.-S. Bai, S.-H. Tu, C. Zhang, and D. Zhu, "Discrete element modeling of progressive failure in a wide coal roadway from water-rich roofs," International Journal of Coal Geology, vol. 167, pp. 215-229, 2016.

[28] F. Gao, D. Stead, and H. Kang, "Simulation of roof shear failure in coal mine roadways using an innovative UDEC Trigon approach," Computers and Geotechnics, vol. 61, pp. 33-41, 2014.

[29] S. Zhang, D. Zhang, H. Wang, and S. Liang, "Discrete element simulation of the control technology of large section roadway along a fault to drivage under strong mining," Journal of Geophysics and Engineering, vol. 15, no. 6, pp. 2642-2657, 2018.

[30] J. Yin, B. Fu, and H. Zhang, "Failure mechanism and control technology for a large-section roadway under weakly cemented formation condition," Geofluids, vol. 2020, Article ID 6669060, 11 pages, 2020.

[31] W.-d. Wu, J.-b. Bai, X.-y. Wang, S. Yan, and S.-x. Wu, "Numerical study of failure mechanisms and control techniques for a gob-side yield pillar in the Sijiazhuang coal mine, China," Rock Mechanics and Rock Engineering, vol. 52, no. 4, pp. 1231-1245, 2019.

[32] C. Qi and A. Fourie, "Cemented paste backfill for mineral tailings management: review and future perspectives," Minerals Engineering, vol. 144, Article ID 106025, 2019.

[33] B. Wu, X. Wang, J. Bai, W. Wu, N. Meng, and H. Lin, “An investigation on the effect of high energy storage anchor on surrounding rock conditions," Royal Society Open Science, vol. 7, no. 10, Article ID 201105, 2020.

[34] F. Q. Gao, Simulation of failure mechanisms around underground coal mine openings using discrete element modeling, Ph.D. thesis, Simon Fraster University, Burnaby, Canada, 2013.

[35] Itasca Consulting Group Inc, UDEC (Universal Distinct Element Code), Version 6.0, Itasca, Minneapolis, MN, USA, 2014.

[36] L. Zhang and H. H. Einstein, "Using RQD to estimate the deformation modulus of rock masses," International Journal of Rock Mechanics and Mining Sciences, vol. 41, no. 2, pp. 337-341, 2004.

[37] M. Singh and K. Seshagiri Rao, "Empirical methods to estimate the strength of jointed rock masses," Engineering Geology, vol. 77, no. 1-2, pp. 127-137, 2005.

[38] M. Cai, "Influence of stress path on tunnel excavation response-numerical tool selection and modeling strategy," Tunnelling and Underground Space Technology, vol. 23, no. 6, pp. 618-628, 2008.

[39] Q.-S. Bai, S.-H. Tu, and C. Zhang, "DEM investigation of the fracture mechanism of rock disc containing hole(s) and its influence on tensile strength," Theoretical and Applied Fracture Mechanics, vol. 86, pp. 197-216, 2016.

[40] J. F. Hazzard and R. P. Young, "Dynamic modelling of induced seismicity," International Journal of Rock Mechanics and Mining Sciences, vol. 41, no. 8, pp. 1365-1376, 2004.

[41] A. Lisjak, Q. Liu, Q. Zhao, O. K. Mahabadi, and G. Grasselli, "Erratum: numerical simulation of acoustic emission in brittle rocks by two-dimensional finite-discrete element analysis," Geophysical Journal International, vol. 196, no. 2, p. 1263, 2014.

[42] J. Yang, M. Fall, and G. Guo, "A three-dimensional hydromechanical model for simulation of dilatancy controlled gas flow in anisotropic claystone," Rock Mechanics and Rock Engineering, vol. 53, no. 9, pp. 4091-4116, 2020.

[43] E. Ghazvinian, M. S. Diederichs, and R. Quey, "3D random voronoi grain-based models for simulation of brittle rock damage and fabric-guided micro-fracturing," Journal of Rock Mechanics and Geotechnical Engineering, vol. 6, no. 6, pp. 506-521, 2014. 